UNEARTHING CONFLICT 



\section{UNEARTHING CONFLICT}

Corporate Mining, Activism, and Expertise in Peru

\section{Fabiana Li}

Duke University Press Durham and London 2015 
Unless otherwise indicated, photos are by the author.

(C) 2015 Duke University Press

All rights reserved

Printed in the United States of America on acid-free

paper $\otimes$

Designed by Heather Hensley

Typeset in Warnock Pro by Tseng Information Systems, Inc.

Library of Congress Cataloging-in-Publication Data

Li, Fabiana, 1976-

Unearthing conflict : corporate mining, activism, and expertise in Peru / Fabiana Li.

pages $\mathrm{cm}$

Includes bibliographical references and index.

ISBN 978-o-8223-5819-o (hardcover : alk. paper)

ISBN 978-0-8223-5831-2 (pbk. : alk. paper)

ISBN 978-o-8223-7586-9 (e-book)

1. Mineral industries - Social aspects - Peru.

2. Mineral industries-Political aspects-Peru.

3. Mineral industries-Economic aspects-

Peru. 4. Mineral industries-Environmental

aspects-Peru. 5. Mines and mineral resources-

Peru. 6. Social conflict-Peru. I. Title.

HD9506.P42L54 2015

$338.20985-\mathrm{dc} 23$

2014038000

Cover art: ( from left) View of Cerro Quilish, from the neighboring community of Tual, photo by author. Opencast mine, Yanacocha Gold Mine, Cajamarca, imageBROKER/Alamy. 